\title{
O PROCESSO DE TERCIARIZAÇÃO DA ECONOMIA E SEU IMPACTO SOBRE O DIREITO DO TRABALHO: A EXPERIÊNCIA DE PORTUGAL
}

THE PROCESS OF TERTIARIZATION OF THE ECONOMY AND ITS IMPACT OVER LABOR LAW: THE EXPERIENCE OF PORTUGAL

\author{
Tales Picchi Alves* \\ Geraldo Henrique de Souza Armond** \\ Cristina Reginato Hoffmann Nascimento ${ }^{* * *}$
}

\begin{abstract}
Resumo:
O presente artigo aborda as transformações impostas à economia de uma nação pelo processo de terciarização de sua economia. Aponta-se as origens fordistas desse processo e seus impactos sobre o Direito do Trabalho, uma vez que a sociedade se depara com novas modalidades de prestação de serviço e a necessidade de regulamenta-las de acordo com os princípios de Direito do Trabalho. Foi escolhido o exemplo de Portugal, por se tratar de um país em que é proibida constitucionalmente a dispensa imotivada. Além disso os legisladores portugueses já elaboraram institutos jurídico-laborais adequados para atender à demanda empresarial para externalizar a prestação de determinados serviços. Pretende-se, portanto, apresentar elementos que enriqueçam o debate no Brasil sobre o assunto.
\end{abstract}

Palavras-chave: Direito do Trabalho. Economia. Terciarização. Externalização.

\begin{abstract}
:
This article discusses the changes imposed on the economy of a nation by the process of tertiarization of its economy. It points out the Fordist origins of this process and its impact on the Labor Law, as society faces new forms of service provision and the need to regulate them in accordance with the principles of Labor Law. Was chosen the example of Portugal, because it is a country in which waiver without cause is prohibited. Moreover the Portuguese legislators have drafted appropriate labor law institutes to meet demand for business outsourcing in the provision of certain services. Therefore, this article intends to present elements to enrich the debate in Brazil on the subject.
\end{abstract}

Keywords: Labor Law. Economics. Tertiarization. Outsourcing.

1. Introdução

O presente estudo tem por objetivo analisar certos aspectos do processo de Terciarização da economia e seus reflexos sobre o Direito do Trabalho, notadamente em

\footnotetext{
Advogado, Mestrando em Direito do Trabalho no Programa de Pós-Graduação da Faculdade de Direito da Universidade de São Paulo.

** Advogado, Especialista em Direito do Trabalho pela USP e Mestrando em Direito do Trabalho no Programa de Pós-Graduação da Faculdade de Direito da Universidade de São Paulo.

*** Advogada, Professora da PUC de Campinas, Especialista em Direito do Trabalho e Mestre em Direito Processual Civil pela PUC de Campinas, Mestranda em Direito do Trabalho no Programa de Pós-Graduação da Faculdade de Direito da Universidade de São Paulo.
} 
Portugal. O Direito do Trabalho deste país tem como principal característica a proibição constitucional da dispensa sem justa causa, o que torna seu estudo bastante profícuo para entender os reflexos que uma proteção desta ordem provoca na legislação trabalhista como um todo e no mercado de trabalho.

A evolução da sociedade moderna tem imposto severas mudanças nos padrões de comportamento humano, em seus mais variados âmbitos. O processo de globalização, aliado aos avanços científicos e tecnológicos obtidos pela humanidade, em especial nos campos que integraram a ciência e a tecnologia da informação aos seus processos funcionais, tais como comunicação, administração, produção etc, são elementos empíricos que reclamam da sociedade a sua imediata adaptação às novas realidades, e, nesse contexto, a relação de trabalho, que exsurge como elemento basilar do sistema de produção capitalista, não fica infensa a tais mudanças.

A pressão por mudanças na ordem trabalhista, geralmente emanadas do sistema econômico, nada obstante o discurso defensor do pleno emprego e, portanto, do trabalhador, revela, de outro lado, a manifesta intenção de flexibilização dos direitos trabalhistas e vai de encontro ao sistema da segurança no emprego. ${ }^{1}$

Isso se dá mediante crítica ao sistema positivista criado a partir do contrato de emprego típico idealizado para o setor secundário, que, para os que defendem mudanças, revela-se um óbice ao progresso econômico e que, no mais das vezes, é acusado de ser o motivo da crise do próprio Direito do Trabalho. ${ }^{2}$ De fato, a introdução de novas tecnologias na estrutura produtiva e as transformações dela decorrentes, principalmente no que toca à necessidade de maior mobilidade em relação ao regime laboral, criaram novas formas legais de prestação de serviços, mais identificadas com o trabalho autônomo, em que a atividade é exercida sem dependência jurídica, formas essas que, ainda que em grau mínimo, contemplam um sistema de proteção laboral. Não se pode negar, desse modo, a dificuldade de delimitação do contrato de trabalho típico em relação ao contrato de prestação de serviços.

Assim, o presente trabalho pretende investigar como a terciarização, numa realidade pós-industrial, é tratada pelo ordenamento trabalhista português ${ }^{3}$ tendo em vista as suas peculiaridades e a demanda empresarial por flexibilização da legislação laboral.

RAMALHO, Maria do Rosário Palma. Insegurança ou diminuição do emprego? A rigidez do sistema jurídico português em matéria de cessação do contrato de trabalho e de trabalho atípico. In: MOREIRA, Antonio (Coord.). X Jornadas Luso-Hispano-Brasileiras de Direito do Trabalho. Coimbra: Almedina, 1999. p. 91.

2 FERRÃO, João. Entender o actual processo de terciarização: das teses às dúvidas. Análise Social, v. 24, p. 101-102, 1988( $\left.2^{\circ}-3^{\circ}\right)$,p. 703-717.Disponívelem: <http://analisesocial.ics.ul.pt/documentos/1223031386S1wGH8bg2Bw91DJ6. pdf $>$. Acesso em: 25 mar. 2009.

3 Constituição da República Portuguesa. Capítulo III. Art. 53º (segurança no emprego): é garantida aos trabalhadores a segurança no emprego, sendo proibidos os despedimentos sem justa causa ou por motivos políticos ou ideológicos. 


\section{Visão econômica do processo de Terciarização}

Para fins analíticos, a ciência econômica estabeleceu uma divisão da atividade produtiva em três setores: o setor primário, o setor secundário e o setor terciário.

No setor primário são consideradas as atividades econômicas que envolvem a exploração direta dos recursos naturais: agricultura, pesca e mineração, por exemplo. O setor secundário, também designado manufatureiro, engloba as atividades pelas quais as matérias-primas obtidas no setor primário são transformadas em produtos: atividade industrial e de transformação. O setor terciário reúne, por sua vez, atividades cujos produtos não têm existência material, como é o caso do comércio e dos serviços.

Em uma economia primitiva, o setor primário abarca grande parte da mãode-obra, fenômeno atualmente encontrado em economias subdesenvolvidas. Os países com essa característica têm seu Produto Interno Bruto sustentado amplamente por atividades agrícolas e de extrativismo natural.

A partir do momento em que a economia de uma nação alcança novos patamares de desenvolvimento, a mão-de-obra começa a ser requisitada para atuar no setor secundário em processos industriais e de transformação. Esse desenvolvimento foi o que se assistiu após as Revoluções Industriais por que passaram diversos países em diferentes períodos da história (final dos séculos XVIII e XIX e meados do século XX), fruto do acúmulo de capital proporcionado por atividades primárias e das inovações tecnológicas conquistadas às respectivas épocas.

Arion Sayão Romita ${ }^{4}$ dá notícia de dois estudos relevantes sobre esse respeito e ratificadores das idéias acima expostas. Segundo esse autor, em 1935 foi publicado o estudo The clash of progress and security pelo economista Allan B. Fisher, em que se analisava a evolução da população ativa em certo número de países. Concluiu-se que no decorrer do desenvolvimento econômico a mão-de-obra se deslocara da agricultura para a indústria e, a seguir, da indústria para o comércio e os serviços. O segundo estudo a que Romita se refere é The conditions of economic progress, de 1940, produzido pelo economista Colin Clark, no qual se retomam as idéias de Fisher, e propõe-se a conclusão “de que o desenvolvimento econômico em todos os países é acompanhado: 1. de importante diminuição dos efetivos do setor primário, tanto em valor absoluto quanto relativo; 2. de progressão, às vezes seguida de estagnação, do setor secundário; 3. enfim, de rapidíssima expansão do setor terciário. Os fatores que determinam essa evolução são, basicamente, o progresso técnico e a evolução do consumo". Clark ainda define o setor terciário como aquele em que se encontram todas as atividades que não têm por objeto elaborar uma produção física.

4 ROMITA, Arion Sayão. A terciarização e o direito do trabalho. Revista LTr, v. 56. n. 03. mar. 1992. p. $273-279$. 
Esse estudo de 1940 descreve o desenrolar de acontecimentos que se seguiram à Segunda Guerra Mundial. As economias desenvolvidas passaram por uma afirmação do Setor Secundário, com base nas práticas Fordistas de organização empresarial e acumulação de capitais. Foram nessas décadas, posteriores a 1945, que a atividade industrial confirmou as bases do Direito do Trabalho como sistema protetor do trabalhador empregado numa relação de subordinação ao seu empregador. O Trabalho dentro de um sistema fordista contava com uma realidade fática passível de ser controlada por normas rígidas sobre local e duração do trabalho, remuneração, pessoalidade e habitualidade da prestação do serviço, por exemplo.

Em estudo sobre a crise do direito laboral, Maria do Rosario Palma Ramalho ${ }^{5}$ estabelece essa conexão entre a relação de trabalho típica e a estrutura fordista de organização empresarial, propondo que a subordinação típica está intimamente ligada à grande unidade industrial em que são facilmente determináveis os aspectos que regem a relação dos trabalhadores com seu empregador e que dão suporte ou são objeto das normas trabalhistas.

Entretanto, nos anos 1970, reuniram-se fatores que apontavam para a fragilização do sistema fordista: após os choques do petróleo (1973 e 1979) e com as inovações tecnológicas, sobretudo nos setores de comunicação e informação principalmente nos anos 1980, o sistema produtivo e as relações de trabalho foram postos em xeque, pois a estrutura produtiva fordista não era mais capaz de aumentar seus ganhos ou, ao menos, manter seus lucros.

Nesse bojo, passou-se a assistir um crescimento intenso do Setor Terciário da economia, nos moldes do modelo proposto por Colin Clark, citado por Romita. ${ }^{6} \mathrm{Na}$ busca por minimização de custos e maximização de lucros, o setor secundário passou a recorrer a prestadores de serviços que fossem capazes de otimizar seus processos produtivos ou oferecer serviços que substituíssem atividades de sua cadeia produtiva a um custo mais baixo do que o de contratar mão-de-obra própria. Dessa forma, começou a crescer a demanda por profissionais de consultoria, para aperfeiçoar o desempenho da atividade industrial (tecnologia da informação, e.g.) e por empresas que se encarregassem de organizar trabalhadores para exercerem funções dentro da indústria, sem serem empregados desta (prestadores de serviço, terciarização, e.g.).

\footnotetext{
RAMALHO, Maria do Rosario Palma. Ainda a crise do direito laboral: a erosão da relação de trabalho "típica" e o futuro do Direito do Trabalho. In: MOREIRA, Antonio (Coord.). III Congresso Nacional de Direito do Trabalho - Memórias. LISBOA: Almedina, 2000. p. 257.

6 ROMITA, Arion Sayão. op. cit.
} 
3. As críticas ao processo de terciarização da economia

A principal crítica ao Setor Terciário é a de que não há produção material de riqueza. Conforme proposto por Clark citado por Romita, as atividades do setor terciário, em oposição à atividade industrial, não têm por objetivo elaborar uma produção física. $\mathrm{O}$ setor terciário tem por característica própria a produção de bens econômicos imateriais, dirigidos à satisfação de alguma necessidade ou carência pela realização de um serviço em favor de alguém.

Esta tese vem desde Adam Smith como aponta o economista francês Jean Gaudrey, ${ }^{7}$ professor emérito da Universidade de Lille I, ao afirmar que as atuais críticas sobre o papel econômico dos Serviços já haviam sido propostas nas primeiras grandes obras de economia política.

Esse economista francês explica que em A Riqueza das Nações, Adam Smith estabeleceu a distinção entre o trabalho produtivo, que agrega valor à matériaprima, e as atividades de serviço, que são improdutivas, pois o trabalho empregado não dá origem a um produto material. Entretanto, Gaudrey afirma que a idéia expressa por Smith dizia respeito aos serviços domésticos, estatais, militares e artísticos, não se comparando às sofisticadas atividades de serviço que foram desenvolvidas a partir dos anos 1980. A despeito disso esse mesmo estudioso relata, em seguida, afirmação de Dominique Strauss$\mathrm{Khan}^{8}$ pela qual o crescimento do setor terciário se daria à reboque da atividade industrial, pois estaria no setor secundário a força de demanda por serviços e somente haveria verdadeiros empregos na indústria.

O sociólogo português, João Ferrão, ${ }^{9}$ apresenta uma posição mais acurada a respeito. Segundo esse estudioso, o processo de terciarização por que a economia vem passando pode ser observado sob duas óticas distintas. De um lado está a posição que vê a Terciarização simplesmente como a expansão do setor econômico em que estão as atividades produtoras de bens imateriais e intangíveis. Por outro lado, pode-se entender que esse processo diz respeito a um movimento maior de reestruturação dos sistemas produtivos "verificando-se um processo de transformação intersectorial baseado na crescente integração das actividades secundárias (e, em menor escala, agrícolas) e terciárias”.

GAUDREY, Jean. Un demi-siècle de montée des services: la révolution permanente. Le Mouvement Social 2005/2 - n. 211. p. 21-36. Disponível em: <http://www.cairn.info/article.php?ID_REVUE=LMS\&ID_ NUMPUBLIE=LMS_211\&ID_ARTICLE=LMS_211_0021>. Acesso em: 01 abr. 2009.

8 Ministro da Economia da França à época desse comentário e atual Diretor-Gerente do Fundo Monetário Internacional - FMI.

9 FERRÃO, João. Entender o actual processo de «terciarização»: das teses às dúvidas. Análise Social, v. XXIV (101-102), $1988\left(2 .^{\circ}-3 .^{\circ}\right)$, p. 703-717. Disponível em: <http://analisesocial.ics.ul.pt/documentos/ 1223031386S1wGH8bg2Bw91DJ6.pdf>, acessado em 25 de março de 2009. 
João Ferrão propõe que não se trata de um declínio do setor industrial em favor do terciário, mas que o processo de terciarização da economia pressupõe a modificação nas relações estabelecidas entre a indústria e os serviços, uma vez que "nem o sector industrial desapareceu, nem os serviços substituíram a produção de bens". Esse autor endossa a afirmação de que o acúmulo de capital tanto na indústria, como nas próprias unidades familiares de consumo, fizeram crescer a demanda por serviços cada vez mais sofisticados. Esse acúmulo de capital, aliado à necessidade premente de reestruturação interna do setor industrial, preparou o caminho para o grande crescimento do setor terciário. Por fim, João Ferrão aponta dois fatores cruciais para o desenvolvimento do setor terciário a partir dos anos 1980: reestruturações organizacionais e tecnológicas, e transformações das condições e modos de consumo.

\section{O fenômeno da terciarização e a realidade de Portugal}

Em Portugal, o conceito de terciarização não é jurídico stricto sensu. É um fenômeno analisado do ponto de vista econômico e sociológico, e tem sido investigado sob dois aspectos: a). como a expansão do setor terciário, ou seja, do setor de serviços (produtor de bens imateriais e intangíveis) e do comércio; ou b). como um movimento de reestruturação dos sistemas produtivos mediante a transformação interssetorial decorrente da crescente integração das atividades secundárias e terciárias. ${ }^{10}$

Dessa forma, a terciarização caracteriza-se como o fenômeno decorrente do deslocamento da economia de um setor eminentemente extrativista para a indústria e da indústria para o comércio e serviços. Significa, assim, o conjunto de atividades econômicas que integra serviços tais como comércio, transportes, finanças, educação, saúde etc. ${ }^{11}$

O termo terciarização é, portanto, um neologismo; é vocábulo construído com base na palavra terciário, do latim tertiariu, que significa terceiro. ${ }^{12}$ Alguns autores,

10 FERREIRA,Aida. A terciarização nofeminino. SERVIÇO SOCIAL NOFEMININO-Jornadas Internacionais. Centro Português de Investigação em História e Trabalho Social - CPIHTS, 51 - 58, junho 1995. Disponível em: $<$ http://www.cpihts.com/PDF/Aida\%20 Ferreira.pdf $>$. Acesso em: 25 mar. 2009. p. 7. A externalização, segundo Gershuny, traduz-se na satisfação de necessidades da indústria através de serviços intermediários realizados por empresas especializadas. Assim, o setor de serviços é visto como oposição ao da produção de bens, traduzindo-se, portanto, na sua imaterialidade.

11 Id. Ibid.

12 Dicionário da Língua Portuguesa da Porto Editora - Acordo Ortográfico. Porto: Porto Editora, 2009. Disponível em www.meusdicionarios.com.br: acesso em 27/03/2009. “Terciário. Adjectivo. 1. Que ocupa o terceiro lugar. 2. De terceira grandeza. 3. ECONOMIA. Relativo ao conjunto de actividades econômicas que integra serviços (comércio, transportes, finanças, educação, saúde, etc.) nome masculino. GEOLOGIA. [com maiúscula] primeiro período do Cenozóico. (Do lat. tertiariu-, «terceiro»)". 
entretanto, utilizam os termos terciarização e externalização como sinônimos, ${ }^{13}$ bem como, da mesma forma, identificam os significados de terciarização e serviços. ${ }^{14}$

Insculpidos na Constituição, em um sistema de normas de eficácia plena, os direitos, liberdades e garantias dos trabalhadores não dependem de regulamentação. Conquanto essa seja a tônica do Direito do Trabalho português, própria de uma constituição dirigente, verifica-se que o direito do trabalho é, também por imposição constitucional, um direito fruto de consensos, da concertação e do diálogo social, tendo resultado, das tensões e concessões dessa pluralidade de forças, a reforma laboral de 2003, com a adoção de um código do trabalho que sofreu nova reforma em 2009. ${ }^{15}$ Como se vê, para a análise proposta neste trabalho, é importante frisar que as relações de trabalho em Portugal são regidas, basicamente, por um código do trabalho.

Para uma melhor compreensão do tema, cumpre ressaltar, também, que a discussão sobre o recurso ao trabalho externo e a necessidade de tratamento legal correspondente só tem sentido em um contexto de segurança no emprego. Inexistente tal instituto jurídico, toda discussão é inócua, na medida em que, nessa hipótese, a opção pela contratação e pela dispensa do trabalhador fica ao inteiro arbítrio do empresário.

Conseqüentemente, à primeira vista, se tomado de forma superficial o argumento empresarial de uma premente necessidade de revisão das leis do trabalho vigentes em Portugal, para conferir maior mobilidade às relações de trabalho, bem assim a exposição de motivos da proposta de Código do Trabalho de 2003, no sentido de que a reforma laboral se deu por necessidade de adequação aos reclamos do sistema econômico (item 3.1), tem-se a impressão de que o regime legal trabalhista fomentou clara e acentuada fuga para o Direito Civil, no qual as partes ocupam posição de maior igualdade $^{16} \mathrm{e}$, com isso, passariam ao largo de institutos trabalhistas consagrados com o aumento do uso de contratos a termo, contratos atípicos etc, tal como o da estabilidade no emprego. Nesse contexto, a legislação trabalhista portuguesa de vanguarda tem sido criticada por um suposto efeito colateral não desejado e não previsto, de precarização das relações laborais. ${ }^{17}$

13 FERREIRA, Aida. op. cit., p. 7.

14 FERRÃO, João. op. cit.

15 BITTENCOURT, Pedro. Dos efeitos perversos da segurança do emprego. In: MOREIRA, Antonio (Coord.). X Jornadas Luso-Hispano-Brasileiras de Direito do Trabalho. Coimbra: Almedina, 1999. p. 106. "O período do 'Direito do Trabalho na crise' tornou claro que a segurança no emprego está indissociavelmente ligada à evolução económico-social. Afirmava-se que o Direito não garante nada que a própria economia não garanta".

16 MOREIRA, António José. Modelo das relações laborais em Portugal. Revista de Direito do Trabalho. n. 122, ano 32, abr/jun., 2006. p. 199.

17 BITTENCOURT, Pedro. op. cit., p. 107. 
Assim, o processo de terciarização da economia, em sentido amplo, abarca o conceito de externalização, o qual se revela pelo aumento da utilização de mecanismos de trabalho atípico, assunto esse de que se ocupa o Direito do Trabalho. Dessa forma, o presente trabalho focará tão-somente os efeitos da terciarização sobre o trabalho subordinado privado mediante o uso de contratos atípicos, na medida em que os demais campos por ela influenciados refogem ao âmbito do direito laboral.

4.1. O processo de terciarização da economia portuguesa

Neste panorama, Portugal se enquadra dentre os países de industrialização tardia, como relata a socióloga portuguesa Aida Ferreira. ${ }^{18}$ Ela sustenta que o processo de terciarização em Portugal ocorreu não só pela demanda produzida pelo setor secundário por serviços, mas, inclusive, pela incapacidade de absorver mão-de-obra apresentada pela incipiente atividade industrial portuguesa.

A título de exemplo sobre a situação européia nesse assunto, depreende-se dos dados expostos na tabela abaixo, que o crescimento da criação líquida de emprego na Europa a partir dos anos 1980 nos setores de atividade terciários foi muito maior que o verificado nos setores ligados à atividade industrial: o indicador sobre a indústria de borracha e plástico apresenta variação de $24,9 \%$, ao passo que os dois itens sobre prestação de serviços propriamente dita, variaram mais de $60 \%$ no período considerado.

\begin{tabular}{|c|c|}
\hline \multicolumn{2}{|l|}{ Tabela I } \\
\hline \multicolumn{2}{|c|}{ Criação líquida de emprego (1980-1995) $^{1}$} \\
\hline Sectores & variação (\%) \\
\hline Serviços colectivos, sociais e pessoais & $65,0 \%$ \\
\hline Serviços financeiros e serviços às empresas & $62,5 \%$ \\
\hline Comércio, hotelaria, restauração & $18,4 \%$ \\
\hline Sectores de tecnologia de ponta & $3,3 \%$ \\
\hline Borracha e plástico & $24,9 \%$ \\
\hline Farmacêutica & $14,6 \%$ \\
\hline Computadores e informática & $8,6 \%$ \\
\hline Transportes e logística & $7,4 \%$ \\
\hline Papel e impressão & $7,3 \%$ \\
\hline Componentes electrónicos & $4,6 \%$ \\
\hline Química & $3,9 \%$ \\
\hline Automóvel & $0,3 \%$ \\
\hline Tecnologia intermédia & $-8,2 \%$ \\
\hline Sectores de baixa tecnologia & $-10,9 \%$ \\
\hline
\end{tabular}

18 FERREIRA, Aida. op. cit. 
Especificamente sobre a situação portuguesa, António Barreto ${ }^{19}$ informa que a distribuição da força de trabalho entre os setores de atividade na economia de Portugal se alterou significativamente desde 1960 até 1998 de acordo com os seguintes dados: o setor primário diminui drasticamente de $43,6 \%$ para $7 \%$; o setor secundário variou positivamente de $28,9 \%$ para $37,9 \%$ e o setor terciário cresceu quase ao dobro, de $27,5 \%$ para $51,3 \%$.

Dados mais recentes são apresentados pelo INE - Instituto Nacional de Estatística de Portugal, dando conta de que em 2005 o setor terciário continuava a aumentar, chegando a abranger 57,6\% do total de empregados do país. ${ }^{20}$ Por fim, segundo estudos do INE ${ }^{21}$ em 2007, “em termos de sectores de actividade (numa lógica tradicional de sector Primário, Secundário e Terciário), Portugal é claramente dominado pelo sector Terciário (dos Serviços), que representa 58,7\% do $\mathrm{VAB}^{22}$ e $62,3 \%$ do emprego total do sector empresarial".

Esses indicadores demonstram inegavelmente a força do fenômeno de terciarização tanto em Portugal como no contexto geopolítico europeu em que está inserido. Para o Direito do Trabalho, importa que 62,3\% dos empregos estão concentrados no Setor Terciário e são as relações estabelecidas neste âmbito que devem chamar a atenção dos juslaboralistas.

Maria do Rosário Palma Ramalho ${ }^{23}$ analisa com propriedade as conseqüências desse fenômeno para as relações entre a empresa e seus trabalhadores. A eminente professora aponta que o desenvolvimento do setor de serviços "acompanhado do desenvolvimento tecnológico e da mundialização da economia, propiciou o surgimento, ao lado das grandes empresas-ilha, de empresas muito mais pequenas, altamente especializadas, competindo internacionalmente e com uma estrutura interna que torna desnecessária certas tarefas e viabiliza amplas reduções de pessoal, em favor do recurso a serviços externos, menos onerosos para os empresários". Nesse ponto surge a questão crucial para a Terciarização que é a dificuldade que as empresas têm em gerenciar seu quadro de trabalhadores, tendo

19 BARRETO, António (Org.). A situação social em Portugal, 1960-1992. v. 2. Lisboa: ICS, 2000. apud CRUZ, Sofia Alexandra. Uma cartografia do trabalho precário, as mulheres (des) alinhadas na precariedade. Porto: Sociologia. n. 12. 2002. p. 164. Disponível em: <http://ler.letras.up.pt/uploads/ficheiros/1493.pdf>. Acesso em: 03 abr. 2009.

20 INSTITUTO NACIONAL DE ESTATÍSTICA - PORTUGAL. INDICADORES SOCIAIS - EDIÇÃO DE 2005. dez, 2006. p. 5. disponível em < http://www.ine.pt> acessado em 02 de abril de 2009.

21 INSTITUTO NACIONAL DE ESTATÍSTICA - PORTUGAL. Seminário "Processos de Reengenharia nas Estatísticas das Empresas”. out, 2007. p. 3. disponível em: <http://www.ine.pt>. Acesso em: 02 abr. 2009.

22 VAB: "valor acrescentado bruto - valor bruto da produção deduzido do custo das matérias-primas e de outros consumos no processo produtivo", segundo Instituto Nacional de Estatística - Portugal, disponível em: <http://metaweb.ine.pt/sim/conceitos/Detalhe.aspx?cnc_cod=4684\&cnc_ini=22-03-2004\%200:00:00>. Acesso em: 02 abr. 2009.

23 RAMALHO, Maria do Rosario Palma. Insegurança ou diminuição do emprego? A rigidez do sistema jurídico português em matéria de cessação do contrato de trabalho e de trabalho atípico. Revista Ltr. v. 64, n. 8, ago. 2000. p. 1.019 . 
em vista o "princípio de segurança no emprego" consagrado no art. $53^{\circ}$ da Constituição da República Portuguesa (CRP).

No capítulo III da CRP, sob o título dos Direitos, liberdades e garantias dos trabalhadores, o art. $53^{\circ}$ (Segurança no emprego) dispõe o seguinte:

É garantida aos trabalhadores a segurança no emprego, sendo proibidos os despedimentos sem justa causa ou por motivos políticos ou ideológicos.

O Código de Trabalho promulgado em 2009 introduz esse preceito fundamental na legislação ordinária, dispondo em seu capítulo VII da Cessação de contrato de trabalho, art. $338^{\circ}$ (Proibição de despedimento sem justa causa):

É proibido o despedimento sem justa causa ou por motivos políticos ou ideológicos.

Tendo em vista a proibição legal de dispensa sem justa causa, os empregadores portugueses têm que encontrar meios de gerenciar sua estrutura empresarial sem poder despedir os trabalhadores contratados. A necessidade de reestruturar o quadro funcional das empresas em velocidade compatível com as mudanças impostas por uma realidade econômica mais dinâmica que a do período fordista, faz com que as empresas recorram a formas alternativas de gerenciar os recursos humanos lançando mão de mecanismos previstos em lei que lhes ofereçam a mobilidade de pessoal necessária à otimização funcional da atividade econômica que exercem.

É nesse contexto que são introduzidas as práticas de externalização: instrumentos que permitem a mobilidade de trabalhadores contratados sem que os trabalhadores sejam dispensados. Nas palavras de Aida Ferreira ${ }^{24}$ "a reorganização do sector secundário conduziu à ampliação do sector terciário através do fenómeno da "externalização" ou "terciarização" - tarefas realizadas por terceiros fora da empresa e que não correspondem à sua vocação principal”.

\section{Externalização}

O recurso ao trabalho externo surge, assim, da descentralização produtiva, com a redução do quadro de empregados e contratação de serviços externos, especialmente, como já mencionado, mediante a utilização de contratos atípicos, restringindo-se a

${ }_{24}$ FERREIRA, Aida. A terciarização no feminino. SERVIÇO SOCIAL NO FEMININO - Jornadas Internacionais. Centro Português de Investigação em História e Trabalho Social - CPIHTS, 51 - 58, junho 1995. Disponível em: <http://www.cpihts.com/PDF/Aida\%20 Ferreira.pdf>. Acesso em: 25 mar. 2009. 
atividade empresarial ao seu núcleo essencial (se o núcleo essencial não for mantido, a empresa perde o seu fim). ${ }^{25} / 26$

Nesse sentido, o Direito do Trabalho português previu, nas reformas de 2003 e 2009, ditos contratos atípicos (cedência, trabalho temporário e pluralidade de empregadores), nas quais tais contratos parecem apresentar-se como uma tentativa de mitigação do nível de proteção dos trabalhadores, conferindo maior mobilidade ao seu rígido regime laboral.

\subsection{Recurso ao trabalho externo e o princípio da segurança no emprego}

O sistema trabalhista português conta com o princípio da segurança no emprego, insculpido no art. 53․ Como visto, não é possível dispensar um trabalhador sem justa causa o que limita a liberdade dos empresários em promover ajustes em sua estrutura produtiva.

Nesse cenário, desenvolveram-se práticas que passaram a ser denominadas de "externalização". Trata-se de mecanismos que permitem ao empregador o recurso a trabalho externo à sua estrutura empresarial sem que precise contratar trabalhadores. Podem ser consideradas como formas de externalização a cedência ocasional de trabalhadores, os trabalhadores temporários cedidos pelas Empresas de Trabalho Temporário - ETT, os trabalhadores contratados por uma pluralidade de empregadores e a celebração de contrato de empreitada com empresa prestadora de serviço.

O contrato de empreitada é utilizado por empresas que tenham a intenção de recorrer a trabalho externo à sua estrutura para realizarem determinadas atividades diversas de seu núcleo essencial por meio de empresas prestadoras de serviço. Nesse caso, celebrase um contrato puramente civilista entre empresas, permitindo que a empresa contratante tenha um quadro de trabalhadores mais enxuto, centrado nas atividades essenciais à sua atividade produtiva e que as atividades ditas não-essenciais sejam realizadas por trabalhadores de empresas especializadas.

$\mathrm{Na}$ cedência ocasional uma empresa cede um tabalhador seu a outra empresa que se utilizará de seus serviços por período de tempo determinado ao fim do qual

25 FERREIRA, Aida. A terciarização no feminino. SERVIÇO SOCIAL NO FEMININO - Jornadas Internacionais. Centro Português de Investigação em História e Trabalho Social - CPIHTS, 51 - 58, junho 1995. Disponível em: <http://www.cpihts.com/PDF/Aida\%20 Ferreira.pdf>. Acesso em: 25 mar. 2009.

26 Id. Ibid. "Nas sociedades onde a industrialização foi tardia, como por ex.: Brasil, Portugal, o sector terciário aparece como resposta às insuficiências da estrutura industrial e de seus limites à incorporação de mão de obra. Este factor conjugado com o processo de urbanização originou o desenvolvimento da terciarização e a conseqüente heterogeneidade do mercado de trabalho. Esta atomização tem a ver com a Empresa Moderna, como também com todos os serviços cuja responsabilidade cabe ao Estado". 
retornará à empresa que o cedera. Nessa hipótese, permite-se a mobilidade do trabalhador sem despedimento; ele trabalha para outra empresa e não perde seu emprego.

As Empresas de Trabalho Temporário são entidades constituídas com o objetivo específico de contratar trabalhadores, oferecer-lhes formação e cede-los para trabalhar em empresas que necessitem dos seus serviços. O trabalhador tem vínculo com a ETT que o cede para exercer seu trabalho em outras empresas. Trata-se, mais uma vez, de hipótese em que o trabalhador tem mobilidade para trabalhar em outras empresas sem necessidade de despedimento.

Por fim, há o caso peculiar da contratação por uma pluralidade de empregadores. Nesse caso, o trabalhador é contratado por um grupo de empresas e tornase lícito o seu deslocamento entre essas empresas para exercer suas atividades. Não haverá necessidade de que seja despedido de uma empresa para vir a integrar a estrutura da outra empresa em que prestará seus serviços. Nesse caso entende-se que o trabalhador não fica adstrito ao quadro funcional de uma só empresa do grupo. Eventualmente, qualquer empresa desse grupo pode vir a utilizar-se dos seus serviços e, quando o fizer, estará recorrendo a trabalho externo à sua estrutura, pois, até aquele momento, esse trabalhador estava exercendo suas atividades dentro da estrutura de outra instituição componente do grupo.

O aspecto que identifica os institutos apontados como formas de externalização é o fato de que, em qualquer dos casos, a empresa que se utilizar desses mecanismos estará recorrendo a trabalhadores externos à sua estrutura empresarial. Com essas hipóteses de externalização, o empresário português tem ao seu dispor maneiras de lidar com o crescente dinamismo do ambiente de negócios e a necessidade de gerenciar sua necessidade por mão-de-obra, minimizando as restrições impostas pelo princípio de segurança no emprego. Pode-se, por exemplo, atender a um aumento temporário de serviços sem que a empresa tenha que contratar e, posteriormente, despedir a mão-de-obra necessária.

\section{Figuras jurídicas relacionadas}

\subsection{Pluralidade de empregadores (Art. $101^{\circ}$ do Código do Trabalho ${ }^{27}$ )}

Empregador é "aquele que, no contrato de trabalho, ocupa a posição de credor da actividade, a prestação de trabalho, sendo devedor da remuneração". ${ }^{28}$

\footnotetext{
27 Lei n. 7/2009. Aprova a revisão do Código do Trabalho.

28 MARTINEZ, Pedro Romano. op. cit., p. 133.
} 
Como explica Martinez, a definição legal anteriormente prevista na LAP (Lei das Associações Patronais) foi suprimida pelo Código do Trabalho de 2003. Definia entidade patronal como "a pessoa, individual ou colectiva, de direito privado, titular de uma empresa que tenha, habitualmente, trabalhadores ao seu serviço". Explica o desajuste da definição, a começar pela possibilidade de pluralidade de empregadores. ${ }^{29}$ Dispõe o art. $101^{\circ}, 1$, do CT que "O trabalhador pode obrigar-se a prestar trabalho a vários empregadores entre os quais exista uma relação societária de participações recíprocas, de domínio ou de grupo, ou que tenham estruturas organizativas comuns". ${ }^{30}$

Segundo Monteiro, "a questão central que a norma regula é a da mobilidade dos trabalhadores no âmbito do grupo entendida como a prestação sucessiva ou simultânea de trabalho por conta e sob a direcção de diversas das pessoas jurídicas que integram aquele". ${ }^{31}$

$\mathrm{O}$ artigo em referência enuncia formalidades quanto à forma escrita e o necessário conteúdo do contrato de trabalho no que diz respeito à identificação das partes e indicação de seu objeto e do empregador que represente os demais empregadores (art. $\left.101^{\circ}, 2\right)$. Entende-se, portanto, que se dá uma relação formal com um empregador e material com vários.

Desta forma, a legislação confere ampla proteção ao trabalhador. Isto porque, inicialmente, reconhece como figura jurídica uma situação fática amplamente difundida, ${ }^{32}$ definindo os contornos jurídicos quanto à sua formalização e disciplinando as obrigações dela decorrentes.

Neste ponto, das obrigações, temos o reconhecimento legal da responsabilidade solidária dos empregadores envolvidos pelo seu cumprimento, seja em relação ao trabalhador ou a terceiros (art. $\left.101^{\circ}, 3\right)$.

Ainda, descaracterizada posteriormente a pluralidade de empregadores, o vínculo contratual fica mantido com o empregador identificado como representante dos demais. Por fim, o não cumprimento das exigências quanto à forma, confere ao trabalhador o direito de optar por um dos empregadores (art. 101 ${ }^{\circ}, 4 / 5$ ).

A exigência da forma escrita com a prévia delimitação de seu objeto, incluindo a indicação da atividade, do local e do período de trabalho, delimita o poder de

29 MARTINEZ, Pedro Romano. op. cit., p. 133-134.

30 CARVALHO, Catarina de Oliveira. A reforma do código do trabalho. Algumas questões sobre a empresa e o direito do trabalho no novo código do trabalho. Coimbra: Coimbra Editora, 2004. p. 439. "Trata-se, assim, de mais um instrumento jurídico a que as partes podem recorrer para conseguirem a circulação interempresarial de trabalhadores".

31 MONTEIRO, Luís Miguel. Código do trabalho anotado. 2. ed. Coimbra: Almedina, 2004. p. 182.

32 "A gênese da solução em análise localiza-se, como referido, na estrutura plural da actividade econômica moderna”. MONTEIRO, Luís Miguel. Código do trabalho anotado. 2. ed. Coimbra: Almedina, 2004. p. 183. 
direção exercido de forma plural. Isto porque assegura ao trabalhador o cumprimento da legislação trabalhista quanto ao exercício da função, à localidade e ao horário conforme contratualmente estipulado. ${ }^{33}$

Os problemas jurídicos observados na prática dos Tribunais relacionam-se, em especial, com a questão da despedida coletiva por motivo de dificuldade econômica, o reconhecimento da sucessão de empresas, a definição da política salarial e a aplicação das convenções coletivas.

Em regra, os Tribunais recorrem ao empregador formal, seja para reconhecer a licitude da despedida ou a sucessão de empresas, ou, para definição da política salarial e da convenção coletiva aplicável, recorrendo-se ao empregador real em situações limite como no caso de falência do empregador formal.

\subsection{Cedência Ocasional (Arts. $288^{\circ}$ a $293^{\circ}$ do Código do Trabalho)}

A cedência ocasional era disciplinada pelos arts. $26^{\circ}$ a $30^{\circ}$ do DecretoLei n. 358/89, de 17 de outubro (lei do trabalho temporário e da cedência ocasional), expressamente revogados pelo Código do Trabalho em $2003,{ }^{34}$ onde a cedência ocasional foi disciplinada pelos arts. $322^{\circ}$ a $329^{\circ}$.

Nos termos do art. $288^{\circ}$ do CT:

A cedência ocasional consiste na disponibilização temporária de trabalhador, pelo empregador, para prestar trabalho a outra entidade, a cujo poder de direção aquele fica sujeito, mantendo-se o vínculo contratual inicial.

Trata-se de uma figura jurídica com dois elementos essenciais, quais sejam a excepcionalidade da cedência e a cisão do poder de direção, com o que se diferencia da figura do trabalho temporário na qual a empresa de trabalho temporário tem por finalidade ceder atividade dos trabalhadores. Nesta, permanece o vínculo empregatício com o cedente que mantém o exercício do poder disciplinar, transferindo-se ao cessionário o exercício do poder de controle e de fiscalização da atividade exercida pelo empregado. ${ }^{35}$

33 "A obrigação de indicar o objecto do contrato de trabalho, o local de execução da prestação e a duração desta explicam-se por razões de tutela do conteúdo funcional da prestação (art. 151, n.1), da inamovibilidade do trabalhador (art. 154) e da duração máxima da jornada de trabalho (idem, art. 163)”. Ibid., p. 183.

34 "Art. $21^{\circ}$ (Norma revogatória). 1 - Com a entrada em vigor do Código do Trabalho são revogados os diplomas respeitantes às matérias nele reguladas, designadamente os seguintes:... n) Arts. $26^{\circ}$ a $30^{\circ}$ do Decreto-Lei n. 358/89, de 17 de outubro (lei do trabalho temporário e da cedência ocasional);...”. Lei n. 99/2003, de 27 de agosto (Código do Trabalho).

35 “A cedência implica uma cisão dos poderes próprios do empregador: o empregador cedente, em princípio, mantém o poder disciplinar sobre o trabalhador cedido e o estatuto de empregador, ao passo que o poder de direcção, na parte atinente à conformação da prestação da actividade e demais condições de trabalho, inscreve-se na esfera jurídica do cessionário". DRAY, Guilherme. Código do trabalho anotado. 2. ed. 
O CT mantém a regra geral, antes prevista na Lei do Trabalho Temporário, da proibição de "ceder trabalhador para utilização de terceiro, salvo nos casos previstos neste Código ou em instrumento de regulamentação colectiva de trabalho" (art. 129, g, do CT).

A proteção do trabalhador consiste na exigência do cumprimento da disciplina contida em instrumento coletivo ou da regulada pelo Código do Trabalho, esta última conforme se expõe a seguir, dependendo nos dois casos da concordância do trabalhador.

Tanto na pluralidade de empregadores quanto na cedência ocasional faz-se necessário que haja algum tipo de ligação societária ou organizativa entre os empregadores envolvidos. Entretanto, a cedência depende de manifestação de vontade do trabalhador, tendo duração máxima de um ano, renovável por iguais períodos até o máximo de cinco anos. Tais são as condições de licitude da cedência ocasional, previstas no art. $289^{\circ}$ do CT.

Em seu art. $290^{\circ}$ o CT exige a forma escrita para formalização ao acordo de cedência ocasional entre cedente e cessionário, com a identificação das partes e do trabalhador cedido, da sua atividade e da duração daquela, dispondo ainda sobre as garantias do trabalhador quando de seu regresso à empresa cedente.

$\mathrm{O}$ não-cumprimento das formalidades exigidas confere ao trabalhador o direito de optar pela permanência ao serviço do cessionário em regime de contrato de trabalho sem termo, mediante comunicação às entidades cedente e cessionária até o termo da cedência, conforme art. $292^{\circ}$ do CT.

Os arts. $291^{\circ}$ e $293^{\circ}$ do CT cuidam, respectivamente, do regime de prestação de trabalho e do enquadramento do trabalhador cedido.

\subsection{Trabalho temporário (Arts. $172^{\circ}$ a $192^{\circ}$ do Código do Trabalho)}

Disciplinado inicialmente pelo Decreto-Lei n. 358/89, revogado pela Lei n. 19/2007. ${ }^{36}$ Sua disciplina foi incluída na revisão do Código do Trabalho, revogando expressamente parte da lei especial. ${ }^{37}$

Coimbra: Almedina, 2004. p. 498.

36 Lei n. 19/2007, de 22 de Maio. Aprova um novo regime do trabalho temporário (revoga o Decreto-Lei n. 358/89, de 17 de Outubro...).

37 “Art. $12^{\circ}$. Norma revogatória. 1 - São revogados: c) As alíneas $d$ ) a f) do art. $2^{\circ}$, os ns. 2 e 9 do art. $6^{\circ}$, os ns. 2 e 3 do art. $13^{\circ}$, os arts. $7^{\circ}, 14^{\circ}$ a $40^{\circ}, 42^{\circ}, 44^{\circ}$ na parte relativa a contra-ordenações por violação de normas revogadas e o n. 1 e as alíneas d) e e) do n. 2 do art. $45^{\circ}$, todos da Lei n. 19/2007, de 22 de maio". Lei n. 7/2009, de 12 de Fevereiro. 
Conhecida como forma de externalização de trabalho por se tratar de contratação que envolve a interposição de uma empresa. ${ }^{38}$ Diferencia-se, neste aspecto, da pluralidade de empregadores e da cedência ocasional uma vez que, nestas figuras, o empregador formal e a empresa cedente não têm por finalidade ceder atividade de seus trabalhadores.

O trabalhador temporário pode ser contratado pela empresa de trabalho temporário de duas formas: por um contrato de trabalho a termo ou por um contrato de trabalho por tempo indeterminado (art. $172^{\circ}$ ), ambos na forma escrita (art. $181^{\circ}$ ).

O exercício da atividade da empresa de trabalho temporário está sujeita a licença, com constituição de caução para garantia dos créditos dos trabalhadores, e sua ausência importa na nulidade dos contratos celebrados entre as empresas e com os trabalhadores, considerando-se "que o trabalho é prestado à empresa de trabalho temporário em regime de contrato de trabalho sem termo" (art. 173, 1/3).

Além disso, dá-se a responsabilidade solidária entre a empresa de trabalho temporário e o utilizador pelos créditos do trabalhador relativos aos últimos três anos (art. $\left.174^{\circ}, 1\right)$.

Importa também em nulidade a celebração de contrato entre empresas de trabalho temporário para cedência do trabalhador a terceiro, considerando-se "que o trabalho é prestado à empresa que contrate o trabalhador em regime de contrato de trabalho sem termo" (art. $\left.173^{\circ}, 2 / 4\right)$.

Inexistindo contrato entre a empresa de trabalho temporário e os trabalhadores na forma exigida pela lei, havendo a cedência para um utilizador "considera-se que o trabalho é prestado a esta empresa em regime de contrato de trabalho sem termo" (art. $\left.173^{\circ}, 5\right)$.

Em todos estes casos, configurada a ilicitude da cedência, cabe ao trabalhador a opção por uma indenização (art. $173^{\circ}, 6$ ). No caso de nulidade do contrato de utilização de trabalho temporário por não observância da forma exigida "considera-se que o trabalho é prestado pelo trabalhador ao utilizador em regime de contrato de trabalho sem termo...", cabendo ao trabalhador a opção por uma indenização (art. 177 ${ }^{\circ}, 4 / 5$ ).

A não observância da forma exigida nos contratos celebrados com os trabalhadores faz considerar "que o trabalho é prestado à empresa de trabalho temporário em regime de contrato de trabalho sem termo", garantida ao trabalhador a opção por uma indenização (arts. $181^{\circ}, 2$ e $183^{\circ}, 3$ ).

\footnotetext{
38 "Não cabendo neste nosso âmbito o estudo específico das origens e desenvolvimento do trabalho temporário, importará em todo o caso assinalar a sua contemporaneidade face a momentos de descentração do próprio processo produtivo, bem como a específicas exigências de natureza econômica, das políticas de emprego e da organização do mercado de trabalho. ASSIS, Rui. O poder de direção do empregador. Configuração geral e problemas actuais. Coimbra: Coimbra Editora, 2005. p. 192.
} 
Havendo descumprimento de créditos do trabalhador pela empresa de trabalho temporário, o utilizador responde subsidiariamente (art. 174 $\left.{ }^{\circ}, 2\right)$.

6.4. Empreitada (Arts. $1207^{\circ}$ e ss. do Código Civil de Portugal)

Contrato de empreitada "é o contrato pelo qual uma das partes se obriga em relação à outra a realizar certa obra, mediante um preço” (art. $1207^{\circ} \mathrm{CC}$ ). O conceito abrange os contratos de subempreitada.

Trata-se de modalidade do contrato de prestação de serviços que, conforme art. $1.155^{\circ}$ do CC abrange três subtipos: o mandato, o depósito e a empreitada. Difere do contrato de trabalho em razão da subordinação jurídica ausente naquele e presente neste. ${ }^{39}$ De fato, no contrato de empreitada a obrigação é de resultado, enquanto no contrato de trabalho a obrigação é de meios, importando o tempo à disposição.

Entretanto, adverte Martinez que "Na noção de obra do art. 1207 do CC inclui-se uma multiplicidade de actividades que podem ser objeto de uma relação laboral" ${ }^{40}$. Desta forma, pela proximidade das duas figuras jurídicas, faz-se sempre necessária uma análise comparativa dos contratos.

A advertência é necessária tendo-se em vista que em se tratando de contrato de trabalho a aplicação do CT é imperativa, na perspectiva de conferir-se efetividade à legislação trabalhista e a adequada proteção ao trabalhador.

Assim, o recurso ao trabalho externo que envolva a realização de certa obra deve observar o respeito ao preceito constitucional de segurança no emprego, amplamente regulamentado no $\mathrm{CT}$.

Evidencia-se o cuidado do legislador ao enunciar no art. $12^{\circ}$ do CT situações em que se presume a existência de contrato de trabalho. Ainda, reconhecendo como “contra-ordenação muito grave imputável ao empregador a prestação de actividade, por forma aparentemente autônoma, em condições características de contrato de trabalho, que possa causar prejuízo ao trabalhador ou ao Estado". ${ }^{41}$

Por outro lado, em seu art. $10^{\circ}$, o CT confere a aplicação de algumas de suas normas, "respeitantes a direitos de personalidade, igualdade e não discriminação e segurança e saúde no trabalho", a situações equiparadas, "em que ocorra prestação de

39 “...; no contrato de trabalho há subordinação jurídica, o que não ocorre na empreitada”. MARTINEZ, Pedro Romano. op. cit., p. 324.

40 MARTINEZ, Pedro Romano. op. cit., p. 324.

41 "Porque nem sempre se torna evidente caracterizar as situações como sendo de prestação de trabalho, o Código do Trabalho, no seu art. $12^{\circ}$, estabelece uma série de presunções da real existência de um contrato de trabalho". CURADO, Armando Antunes. Manual prático de direito do trabalho. 3. ed. Lisboa: Quid Juris Sociedade Editora, p. 85. 
trabalho por uma pessoa a outra, sem subordinação jurídica, sempre que o prestador de trabalho deva considerar-se na dependência econômica do beneficiário da actividade". ${ }^{2}$

\section{Considerações finais}

Como todos os demais países industrializados, Portugal foi afetado pelos efeitos da crise do sistema fordista e das situações que se apresentaram em seguida. A economia portuguesa passou por um processo de terciarização como pôde-se perceber pelos dados apresentados anteriormente e o Direito do Trabalho sofreu mudanças para regular situações fáticas que se mostravam relevantes e introduzir novas normas no ordenamento que servissem a regulamentar apropriadamente aspectos inéditos das relações trabalhistas.

Nesse ambiente, um grande desafio para os legisladores foi o de criar mecanismos que permitissem aos empresários portugueses gerenciar apropriadamente seu quadro de funcionários, mantendo o princípio constitucional de segurança no emprego intocado. Assim, ao longo das últimas décadas, foram realizadas reformas e promulgadas novas leis que sincronizaram o Direito do Trabalho português a necessidade inescapável de modernização da estrutura empresarial.

Dessa forma aperfeiçoou-se a maneira de ceder trabalhadores sem dispensálos inclusive regulamentando fortemente a atividade de empresas especializadas nisso como as Empresas de Trabalho Temporário; entendeu-se lícita a possibilidade de externalizar parte não-essencial da atividade produtiva por meio de contratos de empreitada com empresas especializadas em prestação de serviços e, por fim, criaram-se regras para a possibilidade de um trabalhador ser contratado por um grupo de empresas e poder atuar em todas as instituições que o compõem sem prejuízos para suas condições de trabalho.

A grande lição que se pode extrair da experiência portuguesa perante a realidade pós-fordista e o inevitável processo de terciarização da economia, é a de que foi possível atender às demandas do empresariado, sem abrir mão da proibição de dispensa sem justa causa. Em um sistema que concede aos trabalhadores a maior das proteções por meio do princípio constitucional de segurança no emprego, foi possível mantê-lo e dar mobilidade aos quadros funcionais.

Do estudo do que se denomina recurso ao trabalho externo mediante a adoção de contratos atípicos, infere-se que em nenhum momento a legislação trabalhista de Portugal promoveu qualquer movimento no sentido de flexibilizar direitos dos

\footnotetext{
42 "Art. $10^{\circ}$. Situações equiparadas. As normas legais respeitantes a direitos de personalidade, igualdade e não discriminação e segurança e saúde no trabalho são aplicáveis a situações em que ocorra prestação de trabalho por uma pessoa a outra, sempre que o prestador de trabalho deva considerar-se na dependência econômica do beneficiário da actividade".
} 
trabalhadores. A mencionada reforma legislativa, de forma muito hábil, teve o efeito de mobilidade reclamado pelo sistema econômico, sem transigir com direitos fundamentais dos trabalhadores.

Da leitura das leis que instituíram os ditos contratos atípicos, verifica-se, em uma clara continuidade da tradição protetiva da legislação portuguesa, a blindagem dos direitos dos trabalhadores em face do fenômeno da terciarização da economia, ainda que tais contratos sirvam a uma intenção específica de dar maior mobilidade à mão-de-obra utilizada.

Depreende-se da análise das figuras jurídicas que a regulamentação das formas de mobilidade do trabalhador ou de sua externalização e, portanto, o reconhecimento da descentralização produtiva como uma realidade, trouxe como resultado a proteção do trabalhador, conciliando-se referida realidade com a segurança no emprego.

De fato, o legislador regulamenta formas de descentralização da produção mantendo o vínculo contratual do trabalhador e conferindo inúmeras garantias, como o reconhecimento da responsabilidade solidária ou as exigências quanto à forma dos contratos, disciplinando, ainda, as conseqüências pelo descumprimento das disposições, tais como a configuração de vínculo contratual por prazo indeterminado ou o pagamento de indenização, sem se descuidar das figuras afins.

Deste modo, encontramos nestas figuras jurídicas a realização dos objetivos que constam da Exposição de Motivos da proposta de Código do Trabalho, em especial, quanto à efetividade do Direito do Trabalho.

Campinas-Jundiaí, junho de 2009.

\section{Referências}

ABRANTES, José João. O direito laboral face aos novos modelos de prestação do trabalho. IV Congresso Nacional de Direito do Trabalho, Lisboa, 2001, p. 83-94.

. Direito do trabalho. Ensaios. Edições Cosmos, 1995.

ASSIS, Rui. O poder de direção do empregador. Configuração geral e problemas actuais. Coimbra: Coimbra Editora, 2005.

BARRETO, António (Org.). A situação social em Portugal, 1960-1992. v. 2. LISBOA: ICS, 2000. apud CRUZ, Sofia Alexandra. Uma cartografia do trabalho precário, as mulheres (des) alinhadas na precariedade. Porto: Sociologia. n. 12. 2002. Disponível em <http:/ler.letras.up.pt/uploads/ ficheiros/1493.pdf>. Acesso em: 03 abr. 2009. 
BITTENCOURT, Pedro. Dos efeitos perversos da segurança do emprego. In: MOREIRA, Antônio (Coord.). X Jornadas Luso-Hispano-Brasileiras de Direito do Trabalho. Coimbra: Livraria Almedina, 1999.

CARVALHO, Ana Cristina de Almeida e. A gestão da flexibilidade no emprego através da gestão de recursos humanos: o caso das grandes consultoras de gestão. 2004. Tese (Doutorado) - Universidade do Minho. Cidade de Braga, Portugal. Disponível em: <http://hdl.handle.net/1822/3379>. Acesso em: 24 mar. 2009.

CARVALHO, Catarina de Oliveira. A reforma do código do trabalho. Algumas questões sobre a empresa e o direito do trabalho no novo código do trabalho. Centro de Estudos Judiciários. Inspecção Geral do Trabalho. Coimbra: Coimbra Editora, 2004.

CURADO, Armando Antunes. Manual prático de direito do trabalho. 3. ed. Lisboa: Quid Juris Sociedade Editora.

DiCIONÁRIO DA LÍNGUA PORTUGUESA. Acordo Ortográfico. Porto: Porto Editora, 2009. Disponível em: <www.meusdicionarios.com.br>. Acesso em: 27 mar. 2009.

FERNANDES, António de Lemos Monteiro. Direito do trabalho. 13. ed. Coimbra: Almedina, 2006.

FERRÃO, João. Entender o actual processo de terciarização: das teses às dúvidas. Análise Social, v. XXIV (101-102), $1988\left(2^{\circ}-3^{\circ}\right)$, p. 703-717. Disponível em: <http://analisesocial.ics.ul.pt/ documentos/1223031386S1wGH8bg2Bw91DJ6.pdf>. Acesso em: 25 mar. 2009.

FERREIRA, Aida. A terciarização no feminino. SERVIÇO SOCIAL NO FEMININO - Jornadas Internacionais. Centro Português de Investigação em História e Trabalho Social - CPIHTS, 51 - 58. junho 1995. Disponível em: <http://www.cpihts.com/PDF/Aida\%20 Ferreira.pdf>. Acesso em: 25 mar. 2009.

GAUDREY, Jean. Un demi-siècle de montée des services: la révolution permanente. Le Mouvement Social 2005/2 - n. 211. Disponível em: <http://www.cairn.info/article.php?ID_REVUE=LMS\&ID_ NUMPUBLIE=LMS_211\&ID_ARTICLE=LMS_211_0021>. Acesso em: 01 abr. 2009.

INSTITUTO NACIONAL DE ESTATÍSTICA - Portugal. Indicadores sociais - ed. 2005. dez, 2006. Disponível em: <http://www.ine.pt>. Acesso em: 02 abr. 2009.

INSTITUTO NACIONAL DE ESTATÍSTICA - Portugal. Seminário "Processos de Reengenharia nas Estatísticas das Empresas”. out, 2007. Disponível em: <http://www.ine.pt>. Acesso em: 02 abr. 2009.

OCDE: Second European Report on Scientific and Technological Indicators. (1997: 34) apud MONIZ, António Brandão. Estratégias de construção da Sociedade da Informação. Munich Personal RePEc Archive. Disponível em: <http://mpra.ub.uni-muenchen.de/6633/1/cap_2_EUPT_repec. pdf>. Acesso em: 21 mar. 2009. 
MARTINEZ, Pedro Romano. Direito do trabalho. 3. ed. Coimbra: Almedina, 2006.

. Código do trabalho anotado. 2.ed. Coimbra: Almedina, 2004.

MOREIRA, António José. Modelo das relações laborais em Portugal. Revista de Direito do Trabalho, São Paulo, a. 32, n. 122, abr./jun. 2006.

NOVA ENCICLOPÉDIA ILUSTRADA FOLHA. São Paulo: Editora PUBLIFOLHA - Empresa Folha da Manhã S.A, 1996. v. 2.

RAMALHO, Maria do Rosario Palma. Da autonomia dogmática do direito do trabalho. 1. ed. COIMBRA: Almedina, 2000.

. Insegurança ou diminuição do emprego? A rigidez do sistema jurídico português em matéria de cessação do contrato de trabalho e de trabalho atípico. Revista Ltr, v. 64. n. 8. ago., 2000.

. Ainda a crise do direito laboral: a erosão da relação de trabalho "típica" e o futuro do Direito do Trabalho. In: MOREIRA, Antonio (Coord.). III Congresso Nacional de Direito do Trabalho - Memórias. Coimbra: Almedina, 2000.

REBELO, Glória. Flexibilidade e diversidade laboral em Portugal. Dinâmia - Centro de estudos sobre a mudança socioeconómica. WP n. 2006/50. abril, 2006. Disponível em: <http://loki.iscte. pt:8080/dspace/bitstream/10071/508/1/wp50-2006.pdf>. Acesso em: 02 abr. 2009.

ROMITA, Arion Sayão. A terciarização e o direito do trabalho. Revista LTr, v. 56. n. 03. mar. 1992. 